\title{
Peer Disagreement, Testimony, and Personal Justification
}

\author{
By Nicholas D. Smith ${ }^{*}$
}

In this paper, I consider the problem of peer disagreement: What should one do in a case in which one who is an epistemic peer disagrees with one? One of the flaws with what has come to be known as the "equal weight view" is that it misconceives the asymmetry between the peer's opinion and one's own: the peer's opinion just by itself carries evidential value, whereas one's own just by itself carries none. This shows, I claim, that the evidential weight relevant to a peer's disagreement is that conveyed ordinarily by testimony. I argue against the so-called "total evidence view" that the strategy it mandates cannot be put into practice, because of the objective way in which it conceives of evidence. I conclude by providing my own view, which treats the testimony of peers as testimonial evidence, to be weighed in accordance with one's personal justification system.

Keywords: Peer Disagreement, Testimony, Justification, Social Epistemology, Evidential Weight

\section{Introduction}

The basic problem of peer disagreement is easy enough to state, but has proven much less easy to solve. The problem is this: What should one do in response to disagreement by an epistemic peer? An epistemic peer is one who is a cognitive equal-or close enough. Obviously, the very notion of an epistemic peer has to be indexed to a certain kind of epistemic task or performance: Someone who is my epistemic peer with respect to calculating what each of us should pay as an equal portion for a restaurant bill (a famous case in the literature originally introduced in Christensen, 2007, p. 193hereinafter "RESTAURANT") might not be my epistemic peer with respect to judging what the best option is for a solution to the problem of peer disagreement itself. The problem of peer disagreement occurs when another, who one takes to be an epistemic peer with respect to judgments of a specific sort, disagrees with one in judging such a specific sort of case. What is the rational response to such disagreement? In this paper, I provide my own solution to the problem. Along the way, I will try to show what is right-and what is wrong or at least incomplete-about the other approaches I have encountered in the literature.

*James F. Miller Professor of Humanities, Department of Philosophy, Lewis \& Clark College, USA. 


\section{Equal Weight}

Some epistemologists have proposed what has come to be known as the "Equal Weight View" (which I will refer to as EW henceforth). As one proponent of this view puts it, "When you count an advisor as an epistemic peer, you should give her conclusions the same weight as your own" (Elga, 2007, p. 478). By following this principle broadly, one ends up in what are called "conformist," or "conciliatory" views (see Thune, 2010; Lackey 2010a, 2010b, 2010c): in cases of peer disagreement, one should move towards some conformity or conciliation between the disagreeing peers. One possible outcome of this approach might be suspension of belief until new evidence becomes available to defeat one of the sides of the disagreement.

Now there is surely something right about wanting a conciliatory response to the disagreement of a peer. When I start out by supposing that my own belief has something like a $90 \%$ probability of being true, but then a peer disagrees, it seems right to think that the peer's disagreement should lead me to adjust downward my assessment of the likelihood that I have gotten things right. So one natural way of understanding EW is in terms of a norm to adjust one's assessment of the likelihood that one's initial belief is true. I have no objection against this basic intuition, but even so, I think there is something to note about an asymmetry in the way the problem actually appears to one confronting peer disagreement. The asymmetry has to do with the way we treat the two parts of the disagreement: our own and that of the peer with whom we find ourselves disagreeing.

To see this, we may begin with the fact that reasonable epistemic agents do not put any weight (which I take to mean evidential weight) on their own conclusions, as such. Rather, one perceives certain other factors as having evidential weight, and on the basis of those factors and the weight those factors seem to one to bear, one comes to (reach) the conclusion that one perceives as warranted by that evidence. But all the "weight," if this is so, is borne by what is perceived by the epistemic agent herself as the relevant evidence, and none by the conclusion (all by itself, as it were) that is derived from that evidence. ${ }^{1}$ On the other hand, given the perception of another as an epistemic peer, they assign some weight to the conclusions of their peers. Were that not the case, the problem of peer disagreement would not arise. The problem, in other words, is that the mere appearance of a peer's disagreement carries some weight, once that disagreement is noted by the agent. This seemingly trivial insight, however, has to my knowledge not been made anywhere in the literature, but once observed, I claim, it helps us to see one of the key features of the problem. In brief, the asymmetry observed in this insight reveals that the

\footnotetext{
${ }^{1}$ But cf. White (2009), who argues for treating one's own beliefs as more of less reliable indicators of the facts. This seems too simplistic to me, since one presumably has (and could give) good reasons for such self-trust. So see, Lehrer $(1997 ; 2000)$. Of course, many of our natural cognitive functions may work in such a way as to provide prima facie pro tanto entitlement to their products. See esp. Graham (2012). Even granting this, however, does not seem to provide any support for regarding my beliefs as having evidentiary weight simply on the ground that they are mine.
} 
problem of peer disagreement is a problem that is generated by the simple awareness that a peer disagrees. The asymmetry, then, is the obvious one: one has access to the processes by which one reached one's own conclusion, but not necessarily (or, in some instances, at all) those by which one's peer reached her different conclusion. But even so, the very fact of the peer's disagreement carries weight for the original agent, even without access to what supported it, whereas the very fact of one's own opinion carries no weight except for whatever supports it.

My proposal for how we might best understand this asymmetry is to propose that the perception that a peer disagrees can be treated on a par with the appropriate epistemic response to testimonial evidence. I do not, of course, intend to claim that peer disagreement just is or must always be presented in the form of testimony. I might perceive that an epistemic peer disagrees with me about which line we should be standing in to purchase theater tickets by observing her head for a different line than the one I think is the correct one. But even so, I claim, the way in which we appropriately assess the evidential value of peer disagreement will follow the same approach as we apply to cases of testimonial evidence, since there, too, we assess the evidence provided by recognition of someone else's opinion. ${ }^{1}$ What matters in all such cases is that one is in a position to learn about the opinions of others, and thus to be in a position to gain new information on that basis. To return to the asymmetry noted above, a rational epistemic agent is inclined to give at least some evidential weight to the mere perception that someone one takes to be a peer has some opinion, even without additional access being given to the peer's own evidence or the processes by which the peer came to have that opinion. When one perceived as a peer indicates her opinion, that opinion carries weight with us; when what the peer indicates is disagreement, we feel the weight of the disagreement precisely because, and to the degree that their opinion itself counts as evidence against something(s) we already believe. I conclude that the evidential weight presented in peer disagreement is the kind of evidential weight carried by testimony as a source of information. The beliefs that one might present to peers - one's own conclusions, that is - carry no such weight because one's own conclusions are not source of (new) information to the epistemic agent herself, and that explains the asymmetry. Accordingly, I will characterize such evidence as "testimonial evidence," for the sake of brevity, but mean by this any of the many different ways in which the opinions of others are made available to us.

The asymmetry noted above allows us to see more clearly why, as so many others have noticed (Christensen, 2009, 2011; Frances, 2012; Konigsberg, 2012; Lackey, 2010a, 2010b), different kinds of cases of peer disagreement seem to motivate very different kinds of responses. For example:

\footnotetext{
${ }^{1}$ Others have tried to characterize the evidential weight of the peer's disagreement in terms of what they have called "higher order evidence" (so see, esp. Feldman, 2009; Roush, 2009; Christensen, 2010; Kelly, 2010). I obviously do not think this is the most perspicuous way to conceive of the issue, but I do agree with the general claim that peer testimony can call into question the value of one's (other) evidence for a given position.
} 
ORDINARY PERCEPTION 1: Professor is sitting in her office during office hours, and one of the students from her epistemology class comes in. As Professor makes what she regards as an obvious point to Student, Professor says, "For example, look at the book on this table." Student seems puzzled, "What book?" "The book right here, with a blue cover." Looking down at it, Professor clearly perceives the book right in front of both of them, and both have an unobstructed and clear view. Student shakes his head. "There's no book on the table."

I don't really know what I would do if I were Professor in such a case, but I doubt that I would move in a conciliatory or conforming direction. ${ }^{1}$ This is not because I take my students to be poorer book perceivers than I am. But imagine that Professor continues to look at the book, see it clearly before her, and even reaches out to take it up to offer it to Student to touch and feel for himself. There seems to be no good reason to expect Professor to be suddenly flooded with doubts about her own assessment of whether there is a book on the table. Certainly, the fact of the disagreement is disconcerting. But the professor does not have just this fact to work with. Given so many years of experience with book-perception, it should presumably take a good deal more than a single case of this student's disagreement to have much (if any) effect on Professor's assessment of the situation. At any rate, surely too much in the way of conciliation would be an epistemic fault on Professor's part. Professor's steadfastness ${ }^{2}$ does not seem to me like the error of epistemic "egocentrism" (Lackey, 2010b, p. 275, n. 9) or "bootstrapping" (Elga, 2007, p. 486; opposed by Wedgwood, 2007) — the prejudice of favoring my own beliefs simply because they are mine. It seems, instead, to be plain good sense, at least unless and until Student (somehow) manages to persuade Professor with some other evidence-revealing his covert installation of a hologram machine in Professor's office, or whatever - for his claim that Professor is mistaken. I will provide a diagnosis of how and why this is the right result later on.

\footnotetext{
${ }^{1}$ Contra Feldman, who concludes, of a similar case (involving seeing someone in a blue coat outside his window, and then being confronted with an apparent peer who insisted that there was no one there at all) that "I would not be reasonable in thinking that the problem is in your head, nor would you be reasonable in thinking that the problem is in mine" (Feldman, 2006). Feldman concludes that a strong form of conciliation is required-suspense of judgment. Frances, 2012 thinks that it is more reasonable to think that something has gone wrong with the peer than to think (without any other evidence of malfunction) that something has gone wrong with one's own cognitive operations. Obviously, I agree with Frances here. Lackey provides a similar sort of case ("Directions") in Lackey, 2010a and 2010b.

${ }^{2}$ The general approach that takes the view that it is not irrational to maintain one's original position even in the face of peer disagreement is sometimes called the "Steadfast" view. It is also called the "Nonconformist" or "Extra Weight" view. Those who have argued for the Steadfast view, have, in my opinion, not adequately credited Lehrer's work on self-trust (cf. the first footnote of this article, above) as providing many of the same considerations more recently offered in favor of the view.
} 


\section{Total Evidence}

Another approach to the problem has come to be known as the "total evidence view" (originally named and defended in Kelly, 2005, 2010) which holds that the appropriate response to peer disagreement is determined by the total evidence possessed by the relevant parties. In the original RESTAURANT case, the total evidence seems to favor neither party; in ORDINARY PERCEPTION 1, the total evidence seems strongly to favor Professor's position. But a problem with the total evidence view (TE henceforth) lies in what we are going to count as evidence. After all, there is a perfectly ordinary sense in which one can be in possession of evidence, but not be aware of that evidence as evidence. In such a case, possession would not, as the saying goes, be "9/10ths of the law"; it would not count at all towards what was reasonable for an agent to believe, since reasonableness seems to require actual access, and not mere possession. And part of the problem of peer disagreement is the asymmetry between one's own position to self-assess, relative to evidence, and one's ability to assess the peer's relationship to the evidence. From the objective point of view, the only evidence worth attending to is the good stuff. But if it is only the good stuff that TE wants to count, then TE does not offer any advice that can be actually used, as a practical matter, for the best we can ever do is respond to how the evidence seems to us to indicate (see also Elgin, 2010, who argues that EW mandates an impossible degree of doxastic voluntarism). From the subjective point of view-which is the only point of view we can take when we actually operate in the world - the best we ever do is to try to make the way the evidence seems to us to go align with the way things really are.

So, to the small, but I think important observation made earlier, in regard to the connection between peer disagreement and testimonial evidence (again, very broadly conceived), we can now add another, equally small, but equally important observation: whatever grounds the rationality of a response to peer disagreement will have to be something to which the epistemic agent has access in the subjective sense.

\section{Personal Justification and Disagreement ${ }^{1}$}

Debates about peer disagreement have often been framed in terms of the Scylla of conciliation and the Charybdis of steadfastness. I claim that no general account of proper responses to disagreement can be formulated in these terms. Instead, I have argued that our reactions to peer disagreement seem to be well conceived along the same lines as we respond to evidence from testimony, broadly conceived, and also that appropriate responses to peer disagreement

\footnotetext{
${ }^{1}$ I count the view I go on to develop as at least a close cousin to the view presented by Jennifer Lackey in Lackey (2010a) and (2010b), though perhaps not with the same degree of emphasis as I make on the need for an internalist account of the kind of justification needed. More on this topic to follow below.
} 
(and to testimonial evidence) must be warranted by considerations that are subjectively accessible. To put it more simply, one's responses to evidence of others' opinions will be epistemically appropriate insofar as those reactions are supported by one's personal justification. By "personal justification," I mean only to refer to whatever one recognizes, within one's cognitive system, as justifying a given conclusion-in brief, all of the evidence that is available to one that one recognizes as pertinent evidence (the last stipulation indicates how this view differs from TE and also thus requires an internalist conception of justification; for a full explanation of personal justification, as I am using the term, see Lehrer, 2000; Evans \& Smith, 2012). My proposed solution to the problem of peer disagreement is now easy to state: If one is personally justified in suspending belief, then that is what rationality requires. If (and to the degree that) one is personally justified in remaining steadfast, then steadfastness is mandated. If personal justification in the face of testimony is best achieved or sustained by a reversal of one's original position, then that is what the agent should do.

Grounding the rationality of an agent's response on her personal justification will explain why different kinds of responses to peer disagreement will be appropriate in different sorts of cases. It will turn out that way because the ways in which we must constantly revise and update our cognitive systems in the light of new evidence require both some degree of flexibility (and thus conciliation), and also some degree of steadfastness, depending upon one's assessment of new evidence and also on the prior condition of one's cognitive system. An opinion indicated by one perceived to be an epistemic peer does indeed count as new evidence. But even if the mere perception of another's opinion counts as some reason to accept that opinion, such reason is not isolated from everything else that one already believes, or from every other way an agent receives information. To see how this works more clearly, let us return to the ORDINARY PERCEPTION 1 case, but with a new twist, and with four moments distinguished in sequence:

ORDINARY PERCEPTION 2: (T1) Professor is chatting in the hall with Student, and comes to realize that Student would do well to read Book. She seems to recall leaving Book on her table, and advises Student, "Go into my office and get Book-it's on the table right inside the door." Student agrees and walks to Professor's office. (T2) Student comes back, and says, "It's not there... on the table, that is." Professor, cursing her faulty memory, guides student back toward her office. "Oh, I'm sure it's in there somewhere. I'll find it for you." (T3) Professor reaches the door to her office, looks in, and clearly sees Book on the table, just where she had recalled it as being. "Silly Student! It's right where I told you it was!" But Student responds, "What are you talking about? There's no book there!" (T4) As in ORDINARY PERCEPTION 1, Professor remains steadfast, somewhat flummoxed as to what to do or say to Student at this point. 
Unless there are other factors not included in the example that might be relevant (for example, evidence that others have entered the office in the interims and moved the book around), I contend that Professor's reactions in each moment of the case are rational, and precisely what any good prescriptive theory of epistemic entitlement would mandate. At T2, the Professor has clearly reversed her position, based on memory that Book is on the table. This is what she should do, because Professor rightly recognizes that the evidentiary weight of Student's peer testimony is simply greater than that provided by what she is painfully aware is her often faulty memory. Memory, apart from any other form of evidence, can itself carry different degrees of weight, as evidence. But Professor seems to be reasonable to assess her own ability in casual memories - such as where a book might be in her office-to be not especially trustworthy. Instead, she is inclined to trust her student's testimony, and so at T2, she has stopped believing that Book is on the table, and now thinks it is probably somewhere else in the office-based, again, on other memories she has of where she normally leaves Book and where she has found it in the past. But then, at T3, her belief reverses yet again - this time, she is responding to the overwhelming weight she quite reasonably assigns to her clear perception of Book on the table. Other things equal (again, where there is no evidence that something else might be going on), Professor's clear perception of the book on the table counts as weighty evidence that simply swamps the evidence provided by Student's testimony, which is why Professor is also quite reasonable to remain steadfast in her belief, in spite of the very awkward disagreement in which she now finds herself. The fact that the perceptual evidence actually supports her former memory allows the weak evidence of that memory to be embraced again, but it would be fair to say that this additional evidence - the reestablishment of her memory evidence - counts for little in the new turn of events, for (again, all else being equal) she would also allow vivid perception to swamp some memory she had, as evidence of where Book is at any given moment.

Personal justification is achieved not only by managing the evidence to which one has access, but also by weighing that evidence in a way that best fits with the value such evidence has proven to have within one's cognitive system - the kind of assessment that every rational epistemic agent must do all of the time. Professor is quite aware that she has a faulty casual memory, but she is also aware that she is - or at least has been, as far as she can tellextremely reliable/trustworthy in the uses of perceptual evidence. This is why she allows such evidence to swamp testimonial evidence, and also to swamp casual memory evidence. Were she to fail to do this, she would also fail to achieve personal justification within her system, and would thus fail to be personally justified in the judgments she made as a result. Now, it is true that some of what is contained in her personal justification might be defeated without her awareness. But unless she is aware of such defeat, it is rational for her to judge the way things are in the light of the justification of which she is aware. So sometimes she defers to others' opinions when they disagree with her, in other cases, she suspends belief, because she has no other evidence that 
swamps the opposing testimony but also nothing that adds support to the other's position. But in still other cases, she quite reasonably remains steadfast in her beliefs, on the basis of what she reasonably perceives as justified by the applicable elements of her cognitive system, one element of which is her (also reasonable) self-trust when it comes to making decisions in the face of incomplete or conflicting evidence.

But this means that it could well turn out that the rational thing to do for those who find themselves in disagreement is to shake their heads at each other and agree to disagree. That is because it is natural and normal for each epistemic agent to have a somewhat different cognitive system than any other, and thus for the demands of personal justification to work differently in the face of new evidence. This acknowledges and endorses, obviously, a version of the position in the literature now called epistemic relativism (for which, see Goldman, 2010; Rosen, 2001; see also Bergmann, 2009, and Wedgwood, 2007, who do not, however, apply this term to their views). Two people could each have compelling personal justification for conclusions that are incompatible with those of the other. At this point, one would hope that some form of epistemic charity and respect would apply (as important epistemic virtues): sometimes, when we disagree with apparent peers, there is simply not enough, or the right kind, of evidence available to the disagreeing peers to resolve the disagreement. Steadfastness, in such cases, need not be the same thing as epistemic arrogance.

\section{Conclusion}

In this paper, I have argued, first, that the weight of evidence that is presented in cases of peer disagreement is the very weight we reasonably assign to any indication of the opinions of others, including testimonial evidence. Obviously, we do not always assign the same weight to testimony: We give the testimony of perceived experts (in the appropriate subject-matter, of course) much higher weight, and the testimony of perceived ignoramuses (again, relativized to subject-matter) very low weight - or no weight at all. But my second main claim is that the weight of the evidence provided by indications of the opinions of peers (whether in agreement, disagreement, or in the acquisition of new information) must assessed in the light of the epistemic agent's personal justification regarding the relevant information. As evidence, a peer's opinion might thus simply be swamped by other evidence one takes oneself to have, such that one's personal justification requires simple rejection of the peer's opinion. In other cases, more conciliatory responses might be called for-or even complete capitulation, since the opinion of a peer could in some cases qualify as the most weighty evidence one has available. My solution, then, to the problem of peer disagreement may be stated in brief in a slogan: respond to a peer's disagreement in just the way and to just the degree as you are personally justified in responding. 


\section{Acknowledgements}

I would like to thank the two anonymous reviewers of this paper for their constructive comments.

\section{Bibliography of Sources Cited}

Bergmann, M., 2009. Rational Disagreement after Full Disclosure. Episteme: A Journal of Social Epistemology, 6(3), pp. 336-353.

Christensen, D., 2007. Epistemology of Disagreement: The Good News. Philosophical Review, 116(2), pp. 187-217.

Christensen, D., 2009. Disagreement as Evidence: The Epistemology of Controversy. Philosophy Compass, 4(5), pp. 756-767.

Christensen, D., 2010. Higher-Order Evidence. Philosophy and Phenomenological Research, 81(1), pp. 185-215.

Christensen, D., 2011. Disagreement, Question-Begging and Epistemic Self-Criticism. Philosophers' Imprint, 11(6), pp. 1-22.

Elga, A., 2007. Reflection and Disagreement. Noûs, 41(3), pp. 478-502.

Elgin, C.Z., 2010. Persistent Disagreement. In: R. Feldman \& T.A. Warfield, eds. Disagreement. Oxford: Oxford University Press, pp. 53-68.

Evans, I., \& Smith, N.D., 2012. Knowledge, Cambridge: Polity Press.

Feldman, R., 2006. Epistemological Puzzles about Disagreement. In: S. Hetherington, ed. Epistemology Futures. Oxford: Oxford University Press, pp. 216-236.

Feldman, R., 2009. Evidentialism, Higher-Order Evidence, and Disagreement. Episteme: A Journal of Social Epistemology, 6(3), pp. 294-312.

Frances, B., 2012. Discovering Disagreeing Epistemic Peers and Superiors. International Journal of Philosophical Studies, 20, pp. 1-21.

Graham, P.J., 2012. Epistemic Entitlement. Noûs, 46(3), pp. 449-482.

Goldman, A.I., 2010. Epistemic Relativism and Reasonable Disagreement. In: R. Feldman \& T.A. Warfield, eds. Disagreement. Oxford: Oxford University Press, pp. 187-215.

Kelly, T., 2005. The Epistemic Significance of Disagreement. In: T.S. Gendler \& J. Hawthorne, eds. Oxford Studies in Epistemology, Vol. 1, pp. 167-196.

Kelly, T., 2010. Peer Disagreement and Higher Order Evidence. In: R. Feldman \& T.A. Warfield, eds. Disagreement. Oxford: Oxford University Press, pp. 111174.

Konigsberg, A., 2012. The Problem with Uniform Solutions to Peer Disagreement. Theoria, 15 October 2012 [doi:10.1111/j.1755-2567.2012.01149.x].

Lackey, J., 2010a. A Justificationist View of Disagreement's Epistemic Significance. In: A Haddock, A. Millar, \& D. Pritchard, eds. Social Epistemology. Oxford: Oxford University Press, pp. 298-325.

Lackey, J., 2010b. What Should We Do When We Disagree? In: T.S. Gendler \& J. Hawthorne, eds. Oxford Studies in Epistemology, Vol. 3, pp. 274-293.

Lackey, J., 2010c. Epistemology of Disagreement. [online] Oxford Online Bibliographies. Available from: http://www.oxfordbibliographies.com/view/docume nt/obo-9780195396577/obo-9780195396577-0137.xml;jsessionid= 608D7DA0CCFA 0E844C91E4138F608AB0 [Accessed: 17 June 2015].

Lehrer, K., 1997. Self-Trust: A Study of Reason, Knowledge, and Autonomy. Oxford: Oxford University Press. 
Vol. 2, No. $3 \quad$ Smith: Peer Disagreement, Testimony, and Personal Justification

Lehrer, K., 2000. Theory of Knowledge. $2^{\text {nd }}$ ed. Boulder, CO: Westview Press.

Rosen, G., 2001. Nominalism, Naturalism, Epistemic Relativism. Philosophical Perspectives, 15, pp. 69-91.

Roush, S., 2009. Second Guessing: A Self-Help Manual. Episteme: A Journal of Social Epistemology, 6(3), pp. 251-268.

Thune, M., 2010. 'Partial Defeaters' and the Epistemology of Disagreement. The Philosophical Quarterly, 60(239), pp. 355-372.

Wedgwood, R., 2007. The Nature of Normativity. New York: Oxford University Press.

White, R., 2009. On Treating Oneself and Others as Thermometers. Episteme: A Journal of Social Epistemology, 6(3), pp. 233-250. 